Review Article

\title{
Carbon Monoxide: Anticoagulant or Procoagulant?
}

\author{
Vance G. Nielsen ${ }^{1}$ and Etheresia Pretorius ${ }^{2}$ \\ Pretoria, Arcadia, South Africa \\ Corresponding Author: Vance G. Nielsen, M.D. \\ Department of Anesthesiology \\ The University of Arizona College of Medicine \\ P.O. Box 245114 \\ 1501 North Campbell Avenue \\ Tucson, AZ 85724-5114niels \\ Phone: (520) 626-7999 \\ FAX: (520) 626-6943 \\ Email:vgnielsen@email.arizona.edu
}

Institutional Affiliations: The Department of Anesthesiology ${ }^{1}$, The University of Arizona College of Medicine, Tucson, Arizona, USA; and the Department of Physiology ${ }^{2}$, Faculty of Health Sciences, University of

Grant Support: This investigation was supported by the Departments of Anesthesiology ${ }^{1}$ and Physiology ${ }^{2}$.

\section{ABSTRACT}

Within the past decade there have been several investigations attempting to define the impact of exogenous and endogenous carbon monoxide exposure on hemostasis. Critically, two bodies of literature have emerged, with carbon monoxide mediated platelet inhibition cited as a cause of in vitro human and in vitro/in vivo rodent anticoagulation. In contrast, interaction with heme groups associated with fibrinogen, $\alpha_{2}$-antiplasmin and plasmin by carbon monoxide has resulted in enhanced coagulation and decreased fibrinolysis in vitro in human and other species, and in vivo in rabbits. Of interest, the ultrastructure of platelet rich plasma thrombi demonstrates an abnormal increase in fine fiber formation and matting that are obtained from humans exposed to carbon monoxide. Further, thrombi obtained from humans and rabbits have very similar ultrastructures, whereas mice and rats have more fine fibers and matting present. In sum, there may be 
Nielsen et al. 2

species specific differences with regard to hemostatic response to carbon monoxide. Carbon monoxide may be a Janus-faced molecule, with potential to attenuate or exacerbate thrombophilic disease.

Key Words: 1) carbon monoxide, 2) platelet, 3) fibrinogen, 4) coagulation, 5) fibrinolysis.

The average, healthy human being produces approximately $400 \mu \mathrm{l} /$ hour or 10 $\mathrm{ml} /$ day of carbon monoxide (CO) $[1,2]$ secondary to catabolism of heme by the ubiquitous heme oxygenase system [3], which includes the inducible isoform, heme oxygenase-1 $(\mathrm{HO}-1)$. This results in a normal carboxyhemoglobin $(\mathrm{COHb})$ concentration of less than $1 \%$ in healthy individuals [1]. While these data are well accepted, it is rapidly emerging that CO may be a potential therapeutic agent that can be administered a variety of ways. Particularly, increases in either endogenous $\mathrm{CO}$ production or environmental $\mathrm{CO}$ exposure, may affect hemostasis via modulation of coagulation and fibrinolysis and interestingly this has been noted in several mammalian species [4-76]. There is evidence that excessive CO exposure may result in decreased in vivo and in vitro hemostasis in humans and rodents [4-8,18-23], potentially by inhibition of platelet aggregation [913,15,16,20-23]. However, there is also evidence that increased $\mathrm{CO}$ exposure can enhance platelet activation $[14,17]$ and cause enhanced coagulation/decreased fibrinolysis in humans and other mammalian species [28-47,67-76] via modulation of hemostatically active plasma proteins [48-61,63-66]. The purpose of this review is to compare and contrast these seemingly contradictory bodies of literature and suggest a possible mechanistic/structural reconciliation of the apparently divergent hemostatic effects of $\mathrm{CO}$. 
Nielsen et al. 3

Clinical, preclinical and in vitro evidence that $\mathrm{CO}$ is an anticoagulant and profibrinolytic agent

If CO diminishes hemostasis, it would be expected that there would be some clinically documented hemorrhagic events in the human literature attributed to $\mathrm{CO}$ exposure. Interestingly, hemorrhagic infarction of the brain [4-6], subarachnoid hemorrhage [7], and retinal hemorrhage [8] have been associated with $\mathrm{CO}$ poisoning. As a marker of the degree of exposure, circulating $\mathrm{COHb}$ concentration is typically used, and in the aforementioned case reports the $\mathrm{COHb}$ values varied between $21-35 \%$ [4-8]. While these $\mathrm{CO}$ associated injuries had a hemorrhagic presentation, the authors posited that the combination of hypoxia-reoxygenation and vasodilatation associated with $\mathrm{CO}$ exposure, was the primary mechanism responsible for the acute [7] or subacute [4-6] signs of tissue hemorrhage. Importantly, there were no assessments were made of platelet function or measures of plasmatic coagulation in these patients [4-8].

The mechanism invoked to explain $\mathrm{CO}$ associated decreases in coagulation is that platelet aggregation is affected by $\mathrm{CO}$ a variety of ways [9-16]. In tobacco smokers $[9,10]$, increases in $\mathrm{COHb}$ were not associated with enhancement of platelet aggregation [9] and instead CO exposure was associated with decreased release of adenine diphosphate and serotonin from platelets [10]. Further, $\mathrm{CO}$ inhibits calcium entry into human platelets [11], and appears to decrease platelet aggregation by a mechanism independent of an increase of soluble guanylate cyclase $[12,16]$. It is important to note that these determinations of the effects of $\mathrm{CO}$ on platelet aggregation were performed with carbon monoxide releasing molecules (CORMs) [12,16], which is potentially different from inhaled, environmental exposures. These in vitro findings $[12,16]$ were consistent with the observation that 
platelet soluble guanylate cyclase activity did not correlate with $\mathrm{CO}$ exposure from residential heating of various types [13]. Of interest, an additional, site-directed delivery system of $\mathrm{CO}$ described in rodent models includes intravenous administration of $\mathrm{CO}$ loaded, pegylated hemoglobin [77-79]; however, hemostatic effects of this methodology have not been tested. Lastly, in contrast to platelet aggregation studies, determinations of platelet activation by mean platelet volume in healthy volunteers exposed to passive smoking [14], or victims of CO poisoning [17], have demonstrated enhanced activation following exposure to $\mathrm{CO}$. Unfortunately, the $\mathrm{COHb}$ values of these poisoned patients were not reported [17]; however, the subjects exposed to cigarette smoke showed $\mathrm{COHb}$ value increased by more than $2 \%$ [14]. In sum, there is conflict in the in vitro human literature concerning the effects of $\mathrm{CO}$ on platelet function, and an in vivo investigation involving a pure exposure to $\mathrm{CO}$ (e.g., not CORM or combustion derived $\mathrm{CO}$ ) and subsequent hemostatic evaluation (e.g., bleeding time), remains to be performed.

While in vivo human investigation of the effect of $\mathrm{CO}$ is lacking, there are preclinical rodent models that demonstrate a profibrinolytic and/or antiplatelet effect in vitro and in vivo [18-23]. In hypercholesterolemic mice, upregulation with $\mathrm{HO}-1$ with an adenovirus or exposure to inhaled CO (250 parts per million), decreased thrombus formation following carotid angioplasty, with a decrease in arterial tissue activity of plasminogen activator inhibitor-1, noted [18]. In a rat model of electrical carotid injury and thrombus formation, upregulation of $\mathrm{HO}-1$ activity with hemin administration (an inducer of $\mathrm{HO}-1$ activity) significantly decreased vascular occlusion [19]. In a HO-1 deficient mouse model of allogeneic aortic transplantation, administration of CORMs or wild-type, HO-1 containing platelets prevented graft thrombosis [20]. Similarly, administration of different CORMs 
$[21,22]$ or upregulation of $\mathrm{HO}-1$ [23] in rats, decreased intravascular thrombus formation following vascular injury [21,22], increased tail tip amputation bleeding time [21], and improved hepatic reperfusion following ischemia [23]. The proposed mechanism in most of these works involved platelet inhibition [20-23], and unlike in humans [12,16], rats exhibited a soluble guanylate cyclase dependent mechanism by which $\mathrm{CO}$ decreased platelet aggregation [21]. Critically, the investigations that evaluated plasmatic coagulation function did not demonstrate any important CO mediated hemostatic changes in vitro (e.g., prothrombin time, activated partial thromboplastin time) $[21,22]$. Of interest, there were variable increases in $\mathrm{COHb}$ values in the one study that measured this parameter, with increases in $\mathrm{COHb}$ that were either not significant or increased to approximately $6 \%$ following exposure to CORMs [22]. In other in vitro and in vivo investigations involving either mice or rats [24-27], $\mathrm{COHb}$ concentrations varied following CORM exposure, with little increase seen with CORMs that release CO quickly (e.g., CORM-3, tricarbonyldichloro(glycinato)ruthenium (II)), contrasted with $\mathrm{COHb}$ values between $8 \%$ to $17 \%$ after exposure to slow releasing CORMs (e.g., CORM-A1, sodium boranocarbonate, $\mathrm{Na}_{2}\left[\mathrm{H}_{3} \mathrm{BCO}_{2}\right]$ ). In sum, when exposed to $\mathrm{CO}$ at low or high concentrations (based on $\mathrm{COHb}$ ), platelet function and measures of intravascular thrombus formation were decreased in mice and rats [18-23].

In conclusion, there is anecdotal evidence that $\mathrm{CO}$ exposure has been associated with hemorrhagic phenomena in humans, and there is very convincing evidence that increased endogenous/exogenous $\mathrm{CO}$ exposure has caused decreased hemostasis in rodent species. Platelet inhibition by $\mathrm{CO}$ appears to exist in both human and rodent species, albeit inhibition by different molecular mechanisms. With this in mind, it is 
appropriate to consider the literature that describes thrombophilia associated with $\mathrm{CO}$ exposure in humans and other species as subsequently presented.

\section{Clinical evidence that $\mathrm{CO}$ is a procoagulant and antifibrinolytic agent}

Thrombophilia associated with $\mathrm{CO}$ can be stratified by the degree of exposure and specific thrombotic events. Thus, a consideration of environmental $\mathrm{CO}$ exposure and cardiovascular events as well as cerebral vascular events will be presented initially [28-33]. First, looking at the specific subject's degree of exposure, never smokers in the top quartile of observed circulating $\mathrm{COHb}(0.91 \%)$ were determined to have 3.7 -fold the relative risk of cardiovascular events and 2.2-fold the relative risk of death compared to the quartile with the lowest $\mathrm{COHb}(0.43 \%)$ [28]. Increased environmental presence of $\mathrm{CO}$ in areas with significant [29] or low [30] air pollution was associated with increased incidence of stroke, and increased workplace exposure to $\mathrm{CO}$ [31] in nonsmokers was associated with a 1.97fold increase in ischemic cardiac death. Even more interesting, among tobacco smokers, the degree of increase in $\mathrm{COHb}$ was associated with increased cardiovascular events, stroke and death [32,33]. While supportive of the concept that CO may facilitate thrombophilia in these settings, it must be stressed that none of these settings [28-33] involved exposure to pure $\mathrm{CO}$ without exposure to other potential or actual products of combustion (e.g., fine particulate pollution, tobacco smoke).

However, with regard to effects that are predominantly $\mathrm{CO}$ mediated, the literature concerning the results of $\mathrm{CO}$ poisoning on clinical hemostasis are more substantial. In the case of myocardial infarction, it has been demonstrated that $\mathrm{CO}$ poisoning causes myocardial injury in the presence of normal coronary arteries [34-40] and thrombosis of a 
coronary arterial stent [41], with $\mathrm{COHb}$ values observed as small as $2.6 \%$ [40] to as high as $52.2 \%$ noted [34], with typical values averaging in the $10-20 \%$ range [34-41]. While a likely contributor to myocardial necrosis was hypoxia secondary to decreased oxyhemoglobin and increased $\mathrm{COHb}$, the acute occurrence of coronary artery occlusion/thrombus [38-40] and coronary artery shunt thrombus [41] formation serve as evidence of an acute $\mathrm{CO}$ associated thrombophilic event. Even more impressive are the reports of acute intracardiac thrombus in the right atrium [42-44] or left ventricle [45] and pulmonary embolism [46] in patients with the diagnosis of acute $\mathrm{CO}$ poisoning; unfortunately, only three of these reports documented circulating $\mathrm{COHb}$, which varied between $16 \%$ to $20.2 \%$ [43-45]. In addition to these case reports and series [34-45] portraying a procoagulant feature of marked $\mathrm{CO}$ exposure, one recent article linked in vitro measures of coagulation with clinical $\mathrm{CO}$ poisoning in victims with $\mathrm{COHb}$ concentrations over $10 \%$ [47]. Compared to normal subjects, 48 CO poisoning victims $(\mathrm{COHb}=21.9 \pm 7.9 \%$, mean $\pm \mathrm{SD})$ had significantly greater plasma concentrations of prothrombin fragment $1+2$, plasminogen activator inhibitor-1 and tissue type plasminogen activator with normal fibrinogen concentrations [47]. Spectrophotometric measures of resistance to fibrinolysis also demonstrated that these $\mathrm{CO}$ poisoning victims had increased plasmatic resistance to fibrinolysis [47]. Taken as a whole, these aforementioned investigations potentially link CO exposure to thrombophilia [28-46], with increased systemic thrombin generation and hypofibrinolysis being possible mechanisms by which CO were posited to mediate thrombotic events [47]. 


\section{In vitro and preclinical evidence that $\mathrm{CO}$ is a procoagulant and antifibrinolytic agent}

Late in 2008 it was discovered and subsequently reported that exposure of human plasma to CO released from CORM-2 (tricarbonyldichlororuthenium(II) dimer,

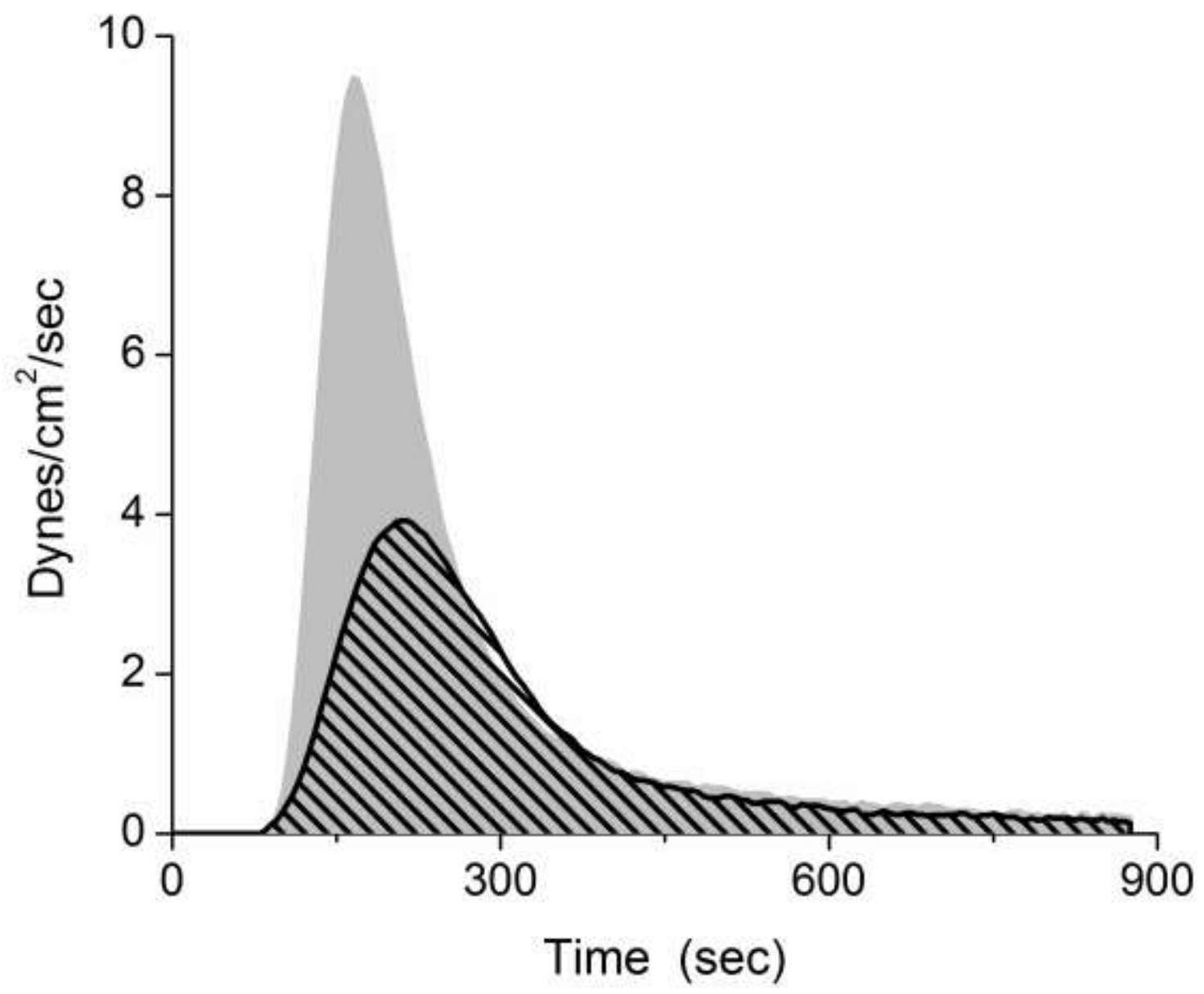

Figure 1. Effects of carbon monoxide derived from CORM-2 on plasma coagulation kinetics. Normal plasma was exposed to $0 \mu \mathrm{M}$ (black hatched trace) or $100 \mu \mathrm{M}$ CORM-2 (light gray solid trace, equivalent to $70 \mu \mathrm{M}$ carbon monoxide) before tissue factor activation in a thrombelastograph. Exposure to carbon monoxide increased the velocity of thrombus growth and overall clot strength. Details of how these data are generated have been previously cited [48]. 
$\left[\mathrm{Ru}(\mathrm{CO})_{3} \mathrm{Cl}_{2}\right]_{2}$ ), increased the velocity of thrombus formation and increased final clot strength; this was determined by thrombelastography using either tissue factor or celite activation [48]. The enhancement of coagulation occurred in both normal and Factor XIII deficient plasma [48], implicating either prothrombin or fibrinogen as the protein being acted upon by $\mathrm{CO}$. An example of coagulation kinetic changes secondary to exposure to CORM-2 in normal plasma is displayed (Fig. 1). It was also subsequently determined that

CO released from CORM-2 decreased tissue-type plasminogen activator (tPA) mediated fibrinolysis in human plasma, a phenomena that all but disappeared in $\alpha_{2}$-antiplasmin deficient plasma, implicating $\alpha_{2}$-antiplasmin and/or plasmin as the molecule(s) modulated by $\mathrm{CO}$ [49]. An example of fibrinolytic kinetic changes, secondary to exposure to CORM-2

in normal plasma, is displayed (Fig. 2). Lastly, it was determined that exposure of normal or FXIII deficient plasma to $\mathrm{CO}$ decreased thick fiber formation and increased fine fiber formation in thrombi, as determined by transmission electron microscopy [50]. In sum, both coagulation and fibrinolysis in human plasma were affected by $\mathrm{CO}$, resulting in faster growing, stronger clots that were more difficult to lyse, with structural changes in thrombus matrix formation present [48-50].

To determine if $\mathrm{CO}$ exposure could be exploited therapeutically to attenuate coagulopathy, several in vitro investigations were conducted wherein various plasma types 


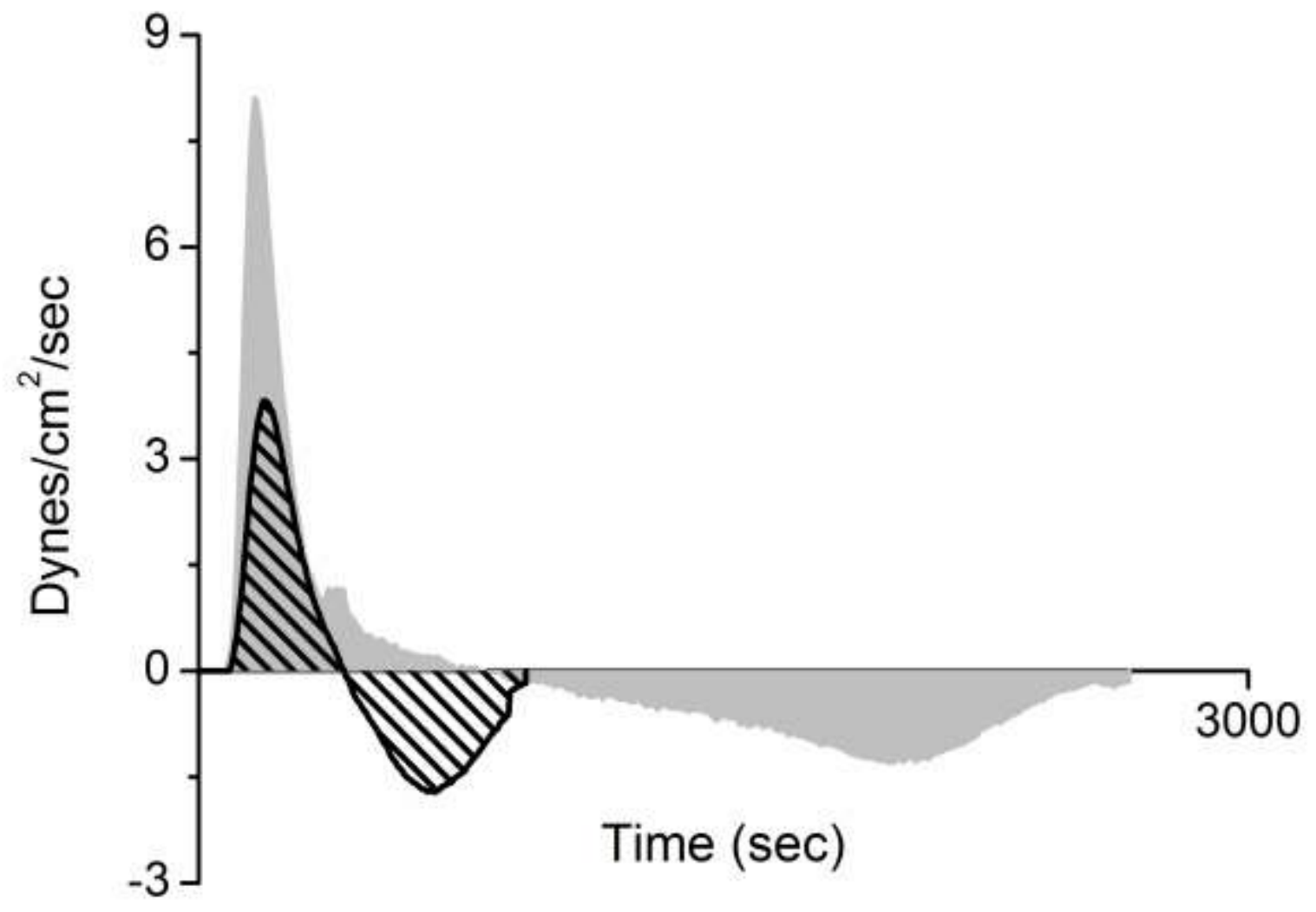

Figure 2. Effects of carbon monoxide derived from CORM-2 on plasma fibrinolytic kinetics. Normal plasma was exposed to $0 \mu \mathrm{M}$ (black hatched trace) or $100 \mu \mathrm{M}$ CORM-2 (light gray solid trace, equivalent to $70 \mu \mathrm{M}$ carbon monoxide) before tissue factor activation and exposure to $100 \mathrm{U} / \mathrm{ml}$ of tissue-type plasminogen activator in a thrombelastograph. Exposure to carbon monoxide increased the velocity of clot growth, increased clot strength, delayed the onset of fibrinolysis, and prolonged clot lysis time. Details of how these data are generated have been previously cited [49].

were exposed to CORM-2 [51-57]. Plasma obtained from individuals with hemophilia A or B [51], or following warfarin administration [52], or following heparin or argatroban exposure [53], or during hypothermia [54], or following hemodilution with either crystalloid or colloidal solutions [55], or following cardiopulmonary bypass [56], or following protamine 
exposure always demonstrated increased velocity of clot formation and strength. And when tested, CORM-2 attenuated TPA mediated fibrinolysis under the aforementioned conditions [52-55,57]. In sum, it appeared that CO could potentially attenuate coagulopathy caused by multiple etiologies.

In order to further characterize the mechanism by which $\mathrm{CO}$ enhanced coagulation, experiments involving isolated exposure of prothrombin [58] or fibrinogen [59] to CORM-2 were performed, with the purified protein function assessed in prothrombin or fibrinogen deficient plasmas, respectively. These works lead to the determination that only fibrinogen was affected by $\mathrm{CO}[58,59]$, and additional work utilizing mass spectrometry [60] demonstrated that protease digestion of fibrinogen was modified by exposure to $\mathrm{CO}$. More importantly, it was noted that a heme group(s) was present in the fibrinogen digest samples, and following exposure of human plasma to compounds that either produced a carboxyheme or metheme state, plasma strength was increased or decreased respectively, indicative of heme-based modulation of fibrinogen function [60]. Exploiting this newfound redox chemistry of fibrinogen, an assay was devised to determine the presence of $\mathrm{CO}$ bound to fibrinogen, named carboxyhemefibrinogen (COHF), as a modification of thrombelastographic methodology [61]. A comparison of a normal subject sample and a sample from a hypercoagulable individual with COHF formation is depicted Fig. 3). The heme and iron binding characteristics of purified fibrinogen have also been confirmed recently by Orino [62]. With regard to the effects of $\mathrm{CO}$ on fibrinolysis, by using varying fibrinolysins and exposing purified $\alpha_{2}$-antiplasmin/plasmin to $\mathrm{CO}$ or nitric oxide ( (NO), it was determined that these two enzymes were involved in the hypofibrinolytic effect 


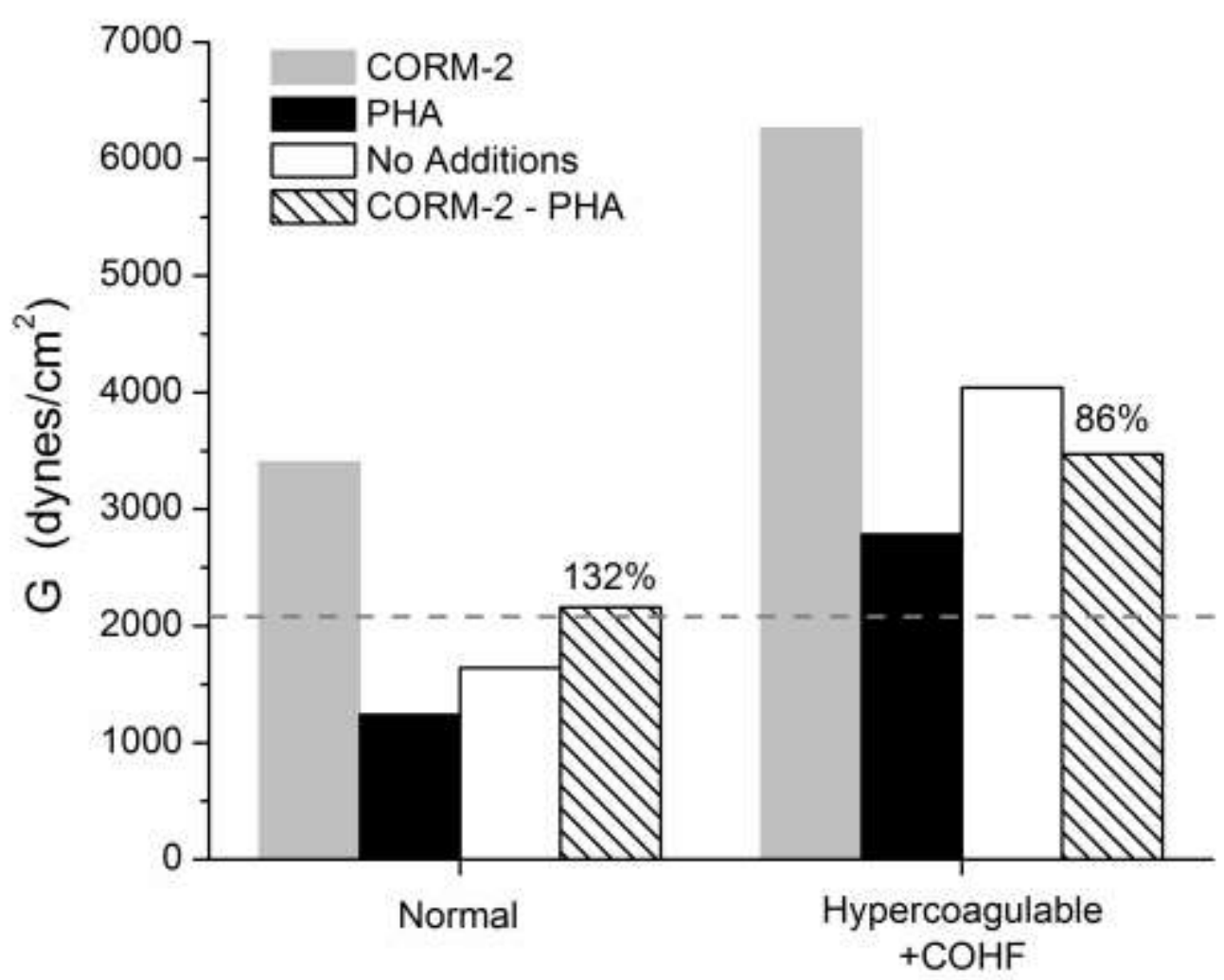

Figure 3. Clot strength based assessment of hypercoagulability and carboxyhemefibrinogen (COHF) formation in a normal subject and a lung cancer patient. Analysis of a normal subject is presented on the left side of this figure, and data from a pathologically hypercoagulable lung cancer patient in a recent study [76] is presented on the right side of the figure. The dashed horizontal line indicates the $95^{\text {th }}$ percentile for normal clot strength determined from 30 normal subjects; the normal subject's plasma strength is below the line, whereas the cancer patient's corresponding value is well above the line (white columns). A carboxyheme state is induced by addition of CORM-2, whereas a metheme state is created by addition of phenylhydroxylamine (PHA). The difference between the two heme states is depicted as a hatched column with corresponding percentage of this difference compared to the sample without additions displayed over the column. The normal difference is $112 \%$; thus, the normal subject is not considered to have carboxyhemefibrinogen (COHF) formation, but the cancer patient is considered to have COHF present. Specific details concerning the conduct of the thrombelastograph-based assay have been previously described [61,71,73-75]. 
of $\mathrm{CO}$, acting via a heme-like mechanism [63-66]. Specifically, $\mathrm{CO}$ exposure enhanced $\alpha_{2^{-}}$ antiplasmin activity $[65,66]$ and decreased plasmin activity [66], whereas exposing these two enzymes to a metheme state resulted in downregulation of the activity of both enzymes [66]. Plasmin was demonstrated to have associated heme, but this investigation could not definitively identify $\alpha_{2}$-antiplasmin associated heme secondary to the inability to digest this heavily glycosylated enzyme [66]. In sum, it appeared that CO modulated key molecules in the coagulation and fibrinolytic pathways and that this is done via heme based mechanisms.

Subsequent investigations that assessed changes in plasma kinetics in vitro and in vivo, were conducted to determine if $\mathrm{CO}$ exposure changed coagulation in various preclinical animal models [67-70]. Of interest, $\mathrm{CO}$ enhanced coagulation and attenuated fibrinolysis in rat, rabbit and horse plasma [67-70]. Further, using a sedated rabbit model measuring ear bleeding times, it was determined that intravenous administration of CORM$2(10 \mathrm{mg} / \mathrm{kg})$ reduced bleeding time to normal values in a model of aspirin/clopidogrel induced platelet inhibition [68]. Similarly, administration of CORM-2 in a similar rabbit model injected with tPA reduced bleeding time several-fold compared to untreated rabbits, with no wound rebleeding noted in CORM-2 treated rabbits [69]. When considering these aforementioned human and animal investigations, it appeared that $\mathrm{CO}$ could promote plasmatic hypercoagulation/hypofibrinolysis via heme-based mechanisms. 
Nielsen et al. 14

Preliminary translational investigations linking $\mathrm{CO}$ exposure to plasmatic hypercoagulability in the setting of smoking, mechanical circulatory support and cancer

Utilizing the aforementioned, thrombelastographically-based assay of plasmatic hypercoagulability and COHF formation [61], the role of excessive exogenous or endogenous $\mathrm{CO}$ exposure was determined in a variety of settings [71-75]. First, twenty healthy smokers without history of thrombotic illness had their plasmatic coagulation analyzed, with the finding that after smoking two cigarettes within a 90 minute period, $45 \%$ were hypercoagulable, $45 \%$ had COHF formation, and $20 \%$ had both conditions [71]. These healthy smoking subjects had a $\mathrm{COHb}$ concentration of $5.0 \pm 2.7 \%$ at the time of the blood collection [71]. Second, a patient with a left ventricular assist device presented with gross hemolysis and partial pump thrombosis; the $\mathrm{COHb}$ varied between $3.1-3.8 \%$ during clinical care, and both hypercoagulability and COHF formation were detected [72]. Third, it was serendipitously noted that a patient undergoing removal of thyroid cancer had plasmatic hypercoagulability; this patient had a $\mathrm{COHb}$ of $2.4 \%$ and was found to have COHF formation [73]. Fourth, in an investigation involving eighteen patients with breast cancer, it was determined that $44 \%$ had plasmatic hypercoagulability, $50 \%$ had COHF formation, 33\% had both hypercoagulability and $\mathrm{COHF}$ formation, and the average $\mathrm{COHb}$ concentration was $2.5 \pm 1.3 \%$ [73]. Fifth, in a similarly designed investigation of twenty patients with brain tumors, it was determined that $50 \%$ had plasmatic hypercoagulability, $60 \%$ had COHF formation, $25 \%$ had both hypercoagulability and COHF formation, and the average $\mathrm{COHb}$ concentration was $1.5 \pm 0.3 \%$ [75]. Sixth, in an investigation of 19 patients with thoracic tumors, it was determined that $84 \%$ had plasmatic hypercoagulability, $44 \%$ of 
these hypercoagulable patients had $\mathrm{COHF}$ formation, and the average $\mathrm{COHb}$ concentration was $2.1 \pm 0.6 \%$ [76]. In all these clinical situations $\mathrm{CO}$ exposure was significant, either as a result of combustion [71] or hemolysis/tumor cell HO-1 upregulation [72-76]. Of particular interest, in the case of exposure of blood to prosthetic biomaterials (e.g., prosthetic heart valves, ventricular assist devices, artificial hearts), there is always the need for anticoagulation, low grade hemolysis is present, and circulating $\mathrm{COHb}$ concentrations between $2-3 \%$ are observed as recently reviewed [80]. Also of interest, when hematin (an HO-1 inducer) has been administered to treat acute porphyria, phlebitis at the injection site has been noted [81], further when hematin in similar doses was administered to healthy volunteers, a picture of intravascular coagulation occurred, with $45 \%$ of the subjects suffering thrombophlebitis [82]. Taken as a whole, in patient populations known to be at risk of thrombotic events, both plasmatic hypercoagulability and COHF formation have been identified [71-76], and patients exposed to $\mathrm{HO}-1$ induction also exhibit signs of hypercoagulability [80-82].

\section{Ultrastructural findings supporting a procoagulant role for $\mathrm{CO}$}

Investigations of platelet poor plasma (PPP) or platelet rich plasma (PRP) obtained from samples exposed to CORM-2 [50], obtained from smokers [83,84], obtained from patients with type II diabetes mellitus [85], and rheumatoid arthritis [86] all display similar 

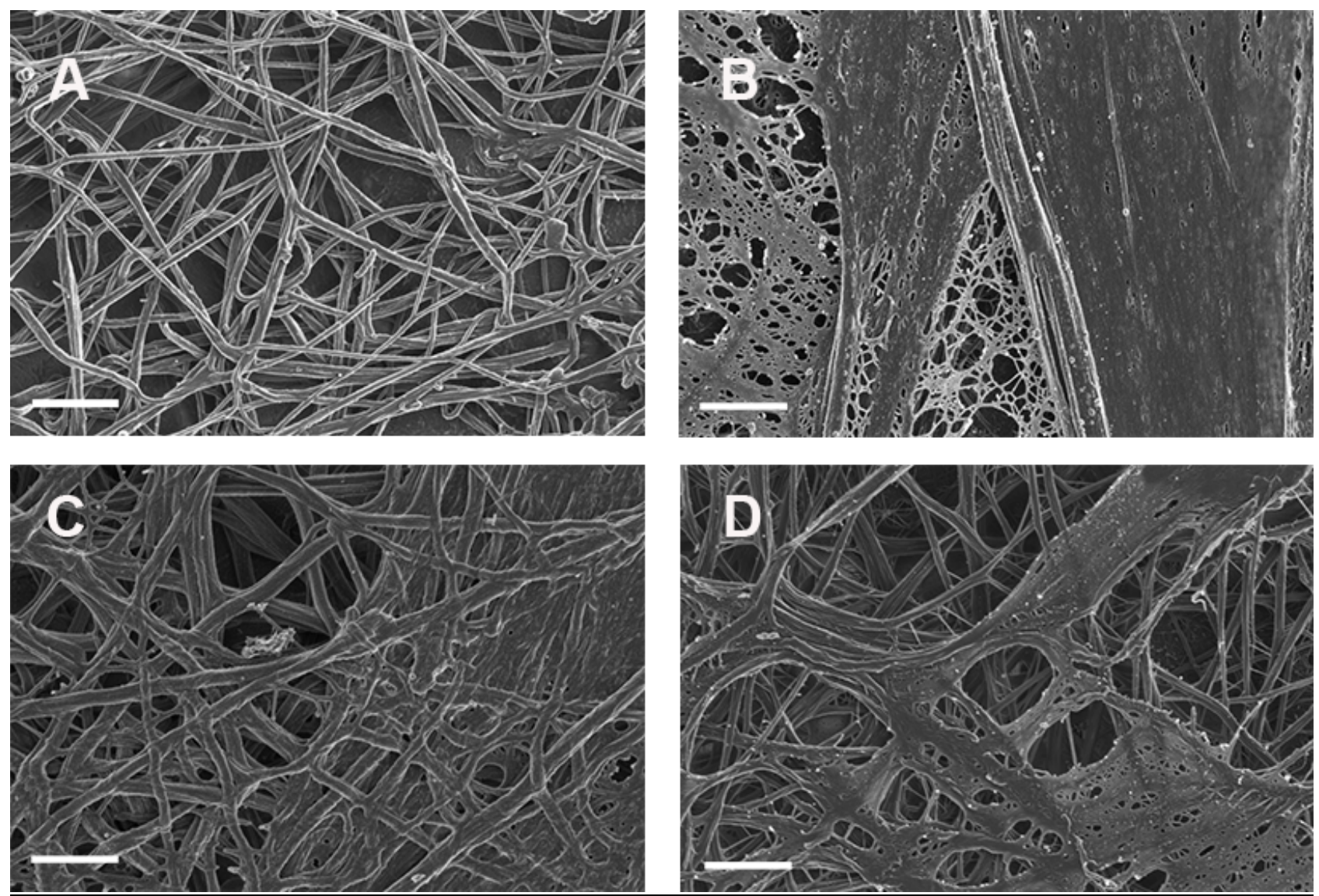

Figure 4. Scanning electron microphotographs of platelet rich plasma thrombi obtained from a normal subject and individuals with various pathological states. Panel $A=$ normal subject plasma, Panel $B=$ plasma obtained from a tobacco smoker, Panel $\mathrm{C}=$ plasma obtained from an individual with type II diabetes mellitus, Panel $\mathrm{D}=$ plasma obtained from an individual with rheumatoid arthritis. Thrombi from the three pathological states have increased thin fibrin polymer formation and matting, and all three states involve increased exposure to either exogenous or endogenous carbon monoxide. Details of how these data are generated have been previously cited [84-86]. White bar $=1 \mu \mathrm{m}$.

features that may be secondary to $\mathrm{CO}$ exposure compared to normal subject plasma. While it may be clear that CO exposure occurs in the case of CORM-2 or cigarette exposure, it should be noted that plasmatic $\mathrm{HO}-1$ activity and/or $\mathrm{COHb}$ concentration is increased in type II diabetes mellitus [87] and rheumatoid arthritis [88,89]. In the case of 
CORM-2 exposure, both normal and factor XIII deficient PPP demonstrated a decrease in large fiber and increase in fine fiber formation as documented by transmission electron microscopy [50]. A similar increase in clot matrix density and fine fiber formation was observed in PPP obtained from smokers as determined by scanning electron microscopy (SEM) [83]. Using PRP, Pretorius and colleagues demonstrated by SEM the formation of not just finer fibers, but also sheet-like matting of thrombus ultrastructure in the settings of smoking [84], type II diabetes mellitus [85] and rheumatoid arthritis [86]. Representative SEM figures of normal PRP and the preceding three conditions are represented (Fig. 4), with methods used to generate these images as previously cited [84-86]. Considered together, these investigations involved conditions or disease states wherein increased CO would be expected to be present, resulting in thrombus ultrastructure (e.g., finer or matted fibers) consistent with enhanced clot strength demonstrated in vitro [48,51-57,67,68,70-76] or in vivo $[68,69]$ following $\mathrm{CO}$ exposure.

However, modulation of fibrinogen-bound heme groups by CO may not be the only mechanism at play in the aforementioned pathological states. First, it has been demonstrated by Lipinski and Pretorius that exposure of purified fibrinogen to ferric ions demonstrated to generate hydroxyl ions without a redox reagent present resulted in aggregation of the fibrinogen [90]. Fenton chemistry may play a role in pathological thrombus formation in diabetes mellitus and other diseases with chronic iron overload [91], and exposure to iron results in SEM evidence of thrombus matting similar to that observed in smoking, diabetes mellitus and rheumatoid arthritis [92,93]. Given the findings of Orino [62] that both iron and heme bind to fibrinogen, it is entirely possible that there are scenarios wherein $\mathrm{CO}$ is the primary modulator of fibrinogen functional change (e.g., 
smoking) contrasted to situations involving both $\mathrm{CO}$ and iron modulating fibrinogen (e.g., hemolysis, engagement of $\mathrm{HO}-1$ and release of $\mathrm{CO}$ and free iron). Indeed, while it is easily argued that the structural changes in thrombi associated with smoking are primarily CO associated, in diabetes mellitus it is likely that iron may have a more prominent role. Nevertheless, the SEM images obtain from smokers or subjects with diabetes mellitus are remarkably similar as displayed (Fig. 4). Future investigation will reveal the role played by either Fenton chemistry or carboxyheme states (or both) in the aforementioned pathological states.

\section{A possible species-specific explanation of disparate hemostatic effects of $\mathrm{CO}$}

Given the preceding bodies of evidence, there is little question that $\mathrm{CO}$ may very well act as either an anticoagulant or procoagulant, depending on the situation and species. Platelets appear to respond to $\mathrm{CO}$ in a similar fashion among human and rodent studies [10-12,16,21,22], but plasmatic coagulation also appears to be enhanced in humans, rats and rabbits [48,51-58,67-69]. In an effort to reveal potential sources of specie specific differences, one may consider the differences in thrombus ultrastructure between humans, rabbits, mice and rats [94,95]. Images of PRP thrombi obtained with SEM reveal a remarkable similarity between humans and rabbits, and a marked difference in structure from mice and rats as displayed (Fig. 5.), which was generated using methods mentioned previously [94,95]. Humans and rabbit thrombi have a less dense matrix, composed of thick and thin fibrin polymers, whereas rodent clots have a more woven, matted structure. How these species-specific differences in ultrastructure impact on plasmatic coagulation kinetics and, ultimately, clinical hemostatic response to $\mathrm{CO}$ is 

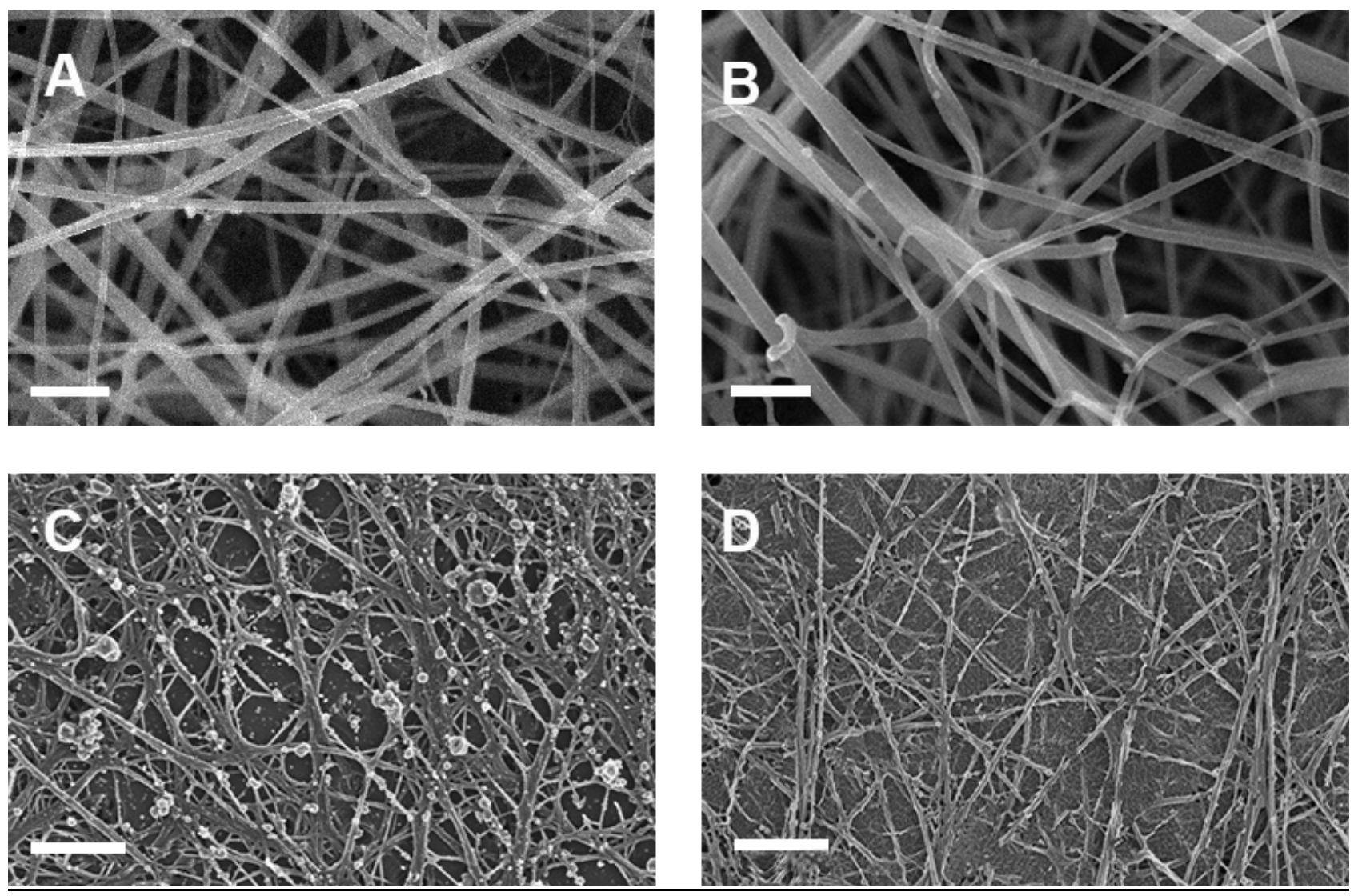

Figure 5. Scanning electron microphotographs of platelet rich plasma thrombi obtained from a human, rabbit, mouse and rat. Panel $\mathrm{A}=$ human plasma, Panel $\mathrm{B}=$ rabbit plasma, Panel $\mathrm{C}=$ mouse plasma, Panel $\mathrm{D}=$ rat plasma. Human and rabbit thrombus fibrin polymer formation is remarkably similar, whereas both rodent thrombi markedly differ from human and rabbit. Details of how these data are generated have been previously cited $[94,95]$. White bar $=1 \mu \mathrm{m}$.

unknown. However, one may speculate that rodents intrinsically have a more robust plasmatic contribution to clot strength, tipping the hemostatic balance more towards bleeding if their platelets are inhibited by $\mathrm{CO}$ exposure. In contrast, perhaps a greater engagement of plasmatic coagulation by $\mathrm{CO}$ in humans, rabbits and other species more than compensates for whatever degree of platelet inhibition may occur, favoring thrombophilia. 


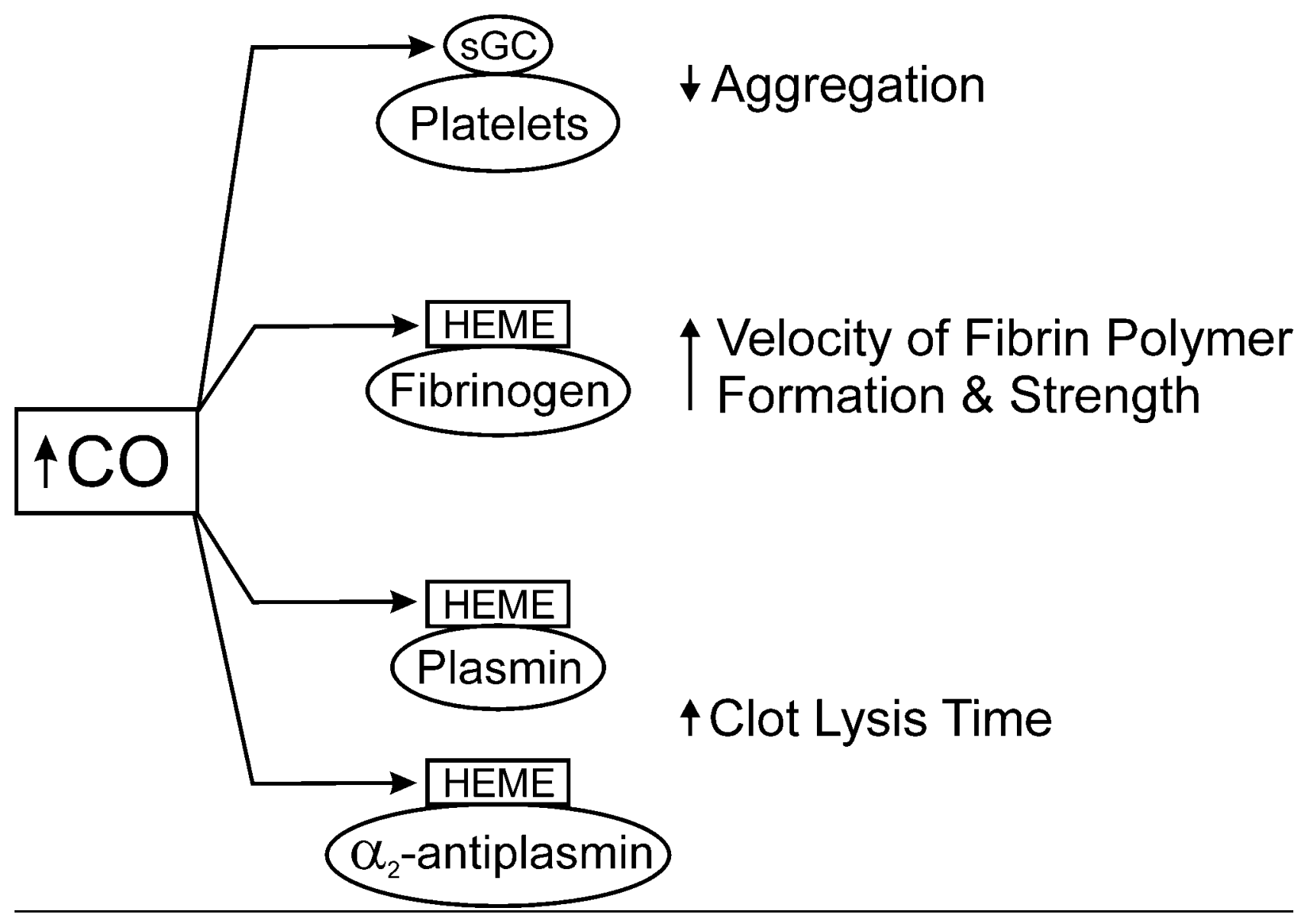

Figure 6. Molecular targets of $\mathrm{CO}$ and effects on coagulation and fibrinolysis. In the presence of increased $\mathrm{HO}-1$ activity or increased exposure to $\mathrm{CO}$ from the environment, the indicated interactions occur in vitro and in vivo. CO decreases platelet aggregation via interaction with soluble guanylate cyclase (sGC) in rodents and decreases aggregation in human platelets by a yet unidentified mechanism. CO interacts with heme groups associated with the indicated molecules, enhancing plasmatic coagulation and attenuating fibrinolysis.

\section{Conclusion}

Within the last decade there has been a marked intensification of investigation to elucidate the effects of $\mathrm{CO}$ on hemostasis. And remarkably, two substantial bodies of evidence have emerged, with $\mathrm{CO}$ being either anticoagulant or procoagulant in nature. The main molecular targets of $\mathrm{CO}$ and the likely effects of these interactions on 
Nielsen et al. 21

coagulation and fibrinolysis are summarized as displayed (Fig. 6). Major gaps in knowledge remain - how will humans respond hemostatically if administered $\mathrm{CO}$ in isolation, with $\mathrm{COHb}$ concentrations increased to values observed in sublethal settings? Does the route of administration (e.g., CORM or inhalation) of CO modify its hemostatic effects? Does the effect of $\mathrm{CO}$ on hemostasis depend on species, or does it also depend on whether the clinical picture presents a more platelet or plasma protein dependent coagulopathy or thrombophilic state? While a great deal of investigation has been conducted, the aforementioned and likely many other questions must be answered before $\mathrm{CO}$ can be touted as a therapeutic agent or thrombophilic pathological agent. Until then, CO remains a Janus-faced molecule, with potential to attenuate or exacerbate thrombophilic disease.

\section{Conflict of Interest}

The authors do not have any conflicts of interest to report concerning the present manuscript.

\section{Funding Source}

Funding for this investigation came solely from departmental sources.

\section{REFERENCES}

1. Owens EO. Endogenous carbon monoxide production in disease. Clin Biochem 2010;43:1183-8.

2. Coburn RF. The measurement of endogenous carbon monoxide production. J Appl Physiol 2012;112:1949-55. 
3. Landaw SA, Callahan EW, Schmid R. Catabolism of heme in vivo: comparison of the simultaneous production of bilirubin and carbon monoxide. J Clin Invest 1970;49:914-25.

4. Finelli F, DiMario FJ Jr. Hemorrhagic infarction in white matter following acute carbon monoxide poisoning. Neurology 2004;63:1102-4.

5. Seet RCS, Wilder-Smith EPV, Lim ECH. Hemorrhagic leukoencephalopathy following acute carbon monoxide poisoning. Eur J Neurol 2008;15:e49-e50.

6. Zhu L, Zhou C, Wu J, Fang S. Rare cerebellar lesions in a carbon monoxide poisoning case. Neurol Sci 2013;DOI 10.1007/s10072-013-1506-6.

7. De-Giorgio F, Grassi VM, Miscusi M, Mancuso C, d'Aloja E, Pascali VL. Subarachnoid hemorrhage and carbon monoxide exposure: accidental association or fatal link? J Forensic Sci 2013;DOI 10.1111/15564029.12168.

8. Kelley JS, Sophocleus GJ. Retinal hemorrhages in subacute carbon monoxide poisoning. Exposures in homes with blocked furnace flues. JAMA 1978;239:1515-17.

9. Renaud S, Blache D, Dumont E, Thevenon C, Wissendanger T. Platelet function after cigarette smoking in relation to nicotine and carbon monoxide. Clin Pharmacol Ther 1984;36:389-95.

10. Mansouri A, Perry CA. Inhibition of platelet ADP and serotonin release by carbon monoxide and in cigarette smokers. Experientia 1984;40:515-7.

11. Gende OA. Carbon monoxide inhibits capacitative calcium entry in human platelets. Thromb Res 2004;114:113-9.

12. Chlopicki S, Olszanecki R, Marcinkiewicz E, Lomnicka M, Motterlini R. Carbon monoxide released by CORM-3 inhibits human platelets by a mechanism independent of soluble guanylate cyclase. Cardiovasc Res 2006;71:393-401.

13. Matthews IP, Henderson KA, Gregory C, Palmer SR, Lang D. Effects of emissions from different type of residential heating upon cyclic guanosine monophosphate (cGMP) in blood platelets of residents. Biomarkers 2010;15:86-93.

14. Yarlioglues M, Ardic I, Dogdu O, Akpek M, Zencir C, Kasapkara HA, Kelesoglu S, Elcik D, Ozdogru I, Oguzhan A, Kaya MG. The acute effects of passive smoking on mean platelet volume in healthy volunteers. Angiology 2012;63:353-7. 
15. Truss NJ, Warner TD. Gasotransmitters and platelets. Pharmacol Ther 2011;132:196-203.

16. Chlopicki S, Lomnicka M, Fedorowicz A, Grochal E, Kramkowski K, Mogielnicki A, Buczko W, Motterlini R. Inhibition of platelet aggregation by carbon monoxide-releasing molecules (CO-RMs): comparison with NO donors. Naunyn-Schmiedeberg's Arch Pharmacol 2012;385:641-50.

17. Karabacak M, Varol E, Turkdogan KA, Duman A, Akpinar O, Karabacak P. Mean platelet volume in patients with carbon monoxide poisoning. Angiology 2013; DOI 10.1177/0003319713497422.

18. Chen $\mathrm{Y}$, Tsai H, Chiang M, Chau L. Carbon monoxide-induced early thrombolysis contributes to heme oxygenase-1-mediated inhibition of neointimal growth after vascular injury in hypercholerterolemic mice. J Biomed Sci 2006;13:721-30.

19. Desbuards N, Rochefort GY, Schlecht D, Machet MC, Halimi JM, Eder V, Hyvelin JM, Antier D. Heme oxygenase-1 inducer hemin prevents vascular thrombosis. Thromb Haemost 2007;98:614-20.

20. Chen B, Guo L, Fan C, Bolisetty S, Joseph R, Wright MM, Agarwal A, George JF. Carbon monoxide rescues heme oxygenase-1-deficient mice from arterial thrombosis in allogeneic aortic transplantation. Am J Pathol 2009;175:422-9.

21. Soni $\mathrm{H}$, Jain M, Mehta AA. Investigation into the mechanism(s) of antithrombotic effects of carbon monoxide releasing molecule-3 (CORM-3). Thromb Res 2011;127:551-9.

22. Kramkowski K, Leszczynska A, Mogielnicki A, Chlopicki S, Fedorowicz A, Grochal E, Mann B, Brzoska T, Urano T, Motterlini R, Buczko W. Antithrombotic properties of water-soluble carbon monoxidereleasing molecules. Arterioscler Thromb Vasc Biol 2012;32:2149-57.

23. Tamura T, Kondo T, Ogawa K, Fukunaga K, Ohkohchi N. Protective effect of heme oxygenase-1 on hepatic ischemia-reperfusion injury through inhibition of platelet adhesion to the sinusoids. J Gastroentero Hepatol 2013;28:700-6.

24. Guo Y, Stein AB, Wu WJ, Tan W, Zhu X, Li QH, Dawn B, Motterlini R, Bolli R. Administration of a CO-releasing molecule at the time of reperfusion reduces infarct size in vivo. Am J Physiol Heart Circ Physiol 2004;286:H1649-53.

25. Motterlini R, Sawle P, Bains S, Hammad J, Alberto R, Foresti R, Green CJ. CORM-A1: a new pharmacologically active carbon monoxide-releasing molecule. FASEB J 2005;19:284-6. 
26. Ryan MJ, Jernigan NL, Drummond HA, McLemore Jr. GR, Rimoldi JM, Poreddy SR, Gadepalli RSV, Stec DE. Renal vascular responses to CORM-A1 in the mouse. Pharmacol Res 2006;54:24-9.

27. De Backer O, Elinck E, Blanckaert B, Leybaert L, Motterlini R, Lefebvre RA. Water-soluble COreleasing molecules reduce the development of postoperative ileus via modulation of MAPK/HO-1 signaling and reduction of oxidative stress. Gut 2009;58:347-56.

28. Hedblad BO, Engstrom G, Janzon E, Berglund G, Janzon L. COHb\% as a marker of cardiovascular risk in never smokers: results from a population-based cohort study. Scand J Public Health 2006;34:609-15.

29. Chan CC, Chuang KJ, Chien LC, Chen WJ, Chang WT. Urban air pollution and emergency admissions for cerebrovascular disease in Taipei, Taiwan. Eur Heart J 2006;27:1238-44.

30. Kettunen J, Lanki T, Tiittanen P, Aalto PP, Koskentalo T, Kulmala M, Salamaa V, Pekkanen J. Associations of fine and ultrafine particulate air pollution with stroke mortality in an area of low air pollution levels. Stroke 2007;38:918-22.

31. Koskela RS, Mutanen P, Sorsa JA, Klockars M. Factors predictive of ischemic heart disease mortality in foundry workers exposed to carbon monoxide. Am J Epidemiol 2000;152:628-32.

32. Hedblad B, Ogren M, Engstrom G, Wollmer P, Janzon. Heterogeneity of cardiovascular risk among smokers is related to degree of carbon monoxide exposure. Atherosclerosis 2005;179:177-83.

33. Hart CL, Smith GD, Hole DJ, Hawthorne VM. Carboxyhaemoglobin concentration, smoking habit, and mortality in 25 years in the Renfrew/Paisley prospective cohort study. Heart 2006;92:321-4.

34. Marius-Nunez AL. Myocardial infarction with normal coronary arteries after acute exposure to carbon monoxide. Chest 1990;97:491-4.

35. Lee D, Hsu TL, Chen CH, Wang SP, Chang MS. Myocardial infarction with normal coronary artery after carbon monoxide exposure: a case report. Chin Med J 1996;57:355-9.

36. Johnson CD. Carbon monoxide toxicity with neurological and cardiac complications. Bol Asoc Med PR 2005;97:315-22.

37. Tucciarone M, Dileo PA, Castro ER, Guerrero M. Myocardial infarction secondary to carbon monoxide poisoning: an uncommon presentation of a common condition. Case report and review of the literature. Am J Ther 2009;16:462-5. 
38. Hsu PC, Lin TH, Su HM, Lee HC, Huang CH, Lai WT, Sheu SH. Acute carbon monoxide poisoning resulting in ST elevation myocardial infarction: a rare case report. Kaohsiung J Med Sci 2010;26:271-5.

39. Isik T, Tanboga IH, Guvenc TS, Uyarel H. ST-elevation myocardial infarction after acute carbon monoxide poisoning. Anadolu Kardiyol Derg 2012;12:278-9.

40. Kim S, Lim JH, Kim Y, Oh S, Choi WG. A case of acute carbon monoxide poisoning resulting in an ST elevation myocardial infarction. Korean Circ J 2012;42:133-5.

41. Dileo PA, Tucciarone M, Castro ER, Guerrero M. Late stent thrombosis secondary to carbon monoxide poisoning. Cardiovasc Revasc Med 2011;12:56-8.

42. Yildirim C, Gunay N, Buyukaslan H. A case of carbon monoxide poisoning with thrombus in the heart. Inhal Toxicol 2005;17:797-801.

43. Choi H, Kim DH, Sun BJ, Kim JS, Yang J, Kim SM, Park SY, Song JM, Kang DH, Song JK. A case of carbon monoxide poisoning with thrombus in right atrium. J Cardiovasc Ultrasound 2012;20:205-8.

44. Ryoo SM, Sohn CH, Kim HJ, Kwak MK, Oh BJ, Lim KS. Intracardiac thrombus formation induced by carbon monoxide poisoning. Hum Exp Toxicol 2013;DOI 10.1177/0960327112472991.

45. Lee SJ, Kang JH, Kim NY, Baek I W, Park MY, Shim BJ, Koh YS, Shin WS, Lee JM, Jeon HK. A case report of carbon monoxide poisoning induced cardiomyopathy complicated with left ventricular thrombus. J Cardiovasc Ultrasound 2011;19:83-6.

46. Sevinc A, Savli H, Atmaca H. An interesting cause of pulmonary emboli: acute carbon monoxide poisoning. Clin Appl Thrombosis/Hemostasis 2005;11:353-7.

47. Gawlikowski T, Gomolka E, Piekoszewski W, Jawien W, Undas A. Acute CO poisoning is associated with impaired fibrinolysis and increased thrombin generation. Basic Clin Pharmacol Toxicol 2013;112:352-6.

48. Nielsen VG, Kirklin JK, George JF. Carbon monoxide releasing molecule-2 increases the velocity of thrombus growth and strength in human plasma. Blood Coagul Fibrinolysis 2009;20:377-80.

49. Nielsen VG, Kirklin JK, George JF. Carbon monoxide releasing molecule-2 (CORM-2) decreases fibrinolysis in human plasma. Blood Coagul Fibrinolysis 2009;20:448-55. 
50. Nielsen VG, Kirklin JK, George JF, Messinger JD. Carbon monoxide releasing molecule-2 decreases thick diameter fibrin fibre formation in normal and factor XIII deficient plasma. Blood Coagul Fibrinolysis 2010;21:101-5.

51. Nielsen VG, Kirklin JK, George JF. Carbon monoxide releasing molecule-2 (CORM-2) increases the velocity of thrombus growth and strength in hemophilia A, hemophilia B and Factor VII deficient plasmas. Blood Coagul Fibrinolysis 2010;21:41-5.

52. Nielsen VG, Khan ES, Kirklin JK, George JF. Carbon monoxide releasing molecule-2 enhances coagulation and diminishes fibrinolytic vulnerability in subjects exposed to warfarin. Thromb Res 2010;126:68-73.

53. Nielsen VG, Khan ES, Kirklin JK, George JF. Carbon monoxide releasing molecule enhances coagulation and diminishes fibrinolytic vulnerability in plasma exposed to heparin or argatroban. Anesth Analg 2010;111:1347-52.

54. Nielsen VG, George SJ. Carbon monoxide releasing molecule-2 attenuates the anticoagulant and amplifies the hypofibrinolytic effects of hypothermia in plasma. Blood Coagul Fibrinolysis 2011;22:67-72.

55. Nielsen VG, Green P, Green M, Martin-Ross A, Khan ES, Kirklin JK, George JF. Carbon monoxide releasing molecule-2 enhances coagulation and diminishes fibrinolytic vulnerability in diluted plasma. $\mathrm{J}$ Trauma 2011;70:939-47.

56. Malayaman SN, Entwistle III JWC, Boateng P, Wechsler AS, Persaud JM, Cohen JB, Kirklin JK, Nielsen VG. Carbon monoxide releasing molecule-2 improves coagulation in patient plasma in vitro following cardiopulmonary bypass. Blood Coagul Fibrinolysis 2011;22:362-8.

57. Nielsen VG, Malayaman SN, Cohen JB, Persaud JM. Carbon monoxide releasing molecule-2 improves protamine-mediated hypocoagulation/hyperfibrinolysis in human plasma in vitro. J Surg Res 2012;173:232-9.

58. Nielsen VG, Malayaman SN, Khan ES, Kirklin JK, George JF. Carbon monoxide releasing molecule2 increases fibrinogen-dependent coagulation kinetics but does not enhance prothrombin activity. Blood Coagul Fibrinolysis 2010;21:349-53. 
59. Machovec KA, Ushakumari DS, Welsby IJ, Nielsen VG. The procoagulant properties of purified fibrinogen concentrate are enhanced by carbon monoxide releasing molecule-2. Thromb Res 2012;129:7936.

60. Nielsen VG, Cohen JB, Malayaman SN, Nowak M, Vosseller K. Fibrinogen is a heme-associated, carbon monoxide sensing molecule: a preliminary report. Blood Coagul Fibrinolysis 2011;22:443-7.

61. Nielsen VG, Arkebauer MR, Vosseller K. Redox-based thrombelastographic method to detect carboxyhemefibrinogen mediated hypercoagulability. Blood Coagul Fibrinolysis 2011;22:657-61.

62. Orino K. Functional binding analysis of human fibrinogen as an iron- and heme-binding protein. Biometals 2013;DOI 10.1007/s10534-013-9657-8.

63. Nielsen VG. The antifibrinolytic effects of carbon monoxide releasing molecule-2 are fibrin and $\alpha_{2^{-}}$ antiplasmin dependent. Blood Coagul Fibrinolysis 2010;21:584-7.

64. Cohen JB, Persaud JM, Malayaman SN, Nielsen VG. Carbon monoxide releasing molecule-2 enhances coagulation and attenuates fibrinolysis by two mechanisms: insights gained with colloid dilution. Blood Coagul Fibrinolysis 2011;22:60-6.

65. Malayaman SN, Nielsen VG, Cohen JB, Machovec KA, Bernhardt BE, Arkebauer MR. Carbon monoxide releasing molecule-2 enhances alpha-2-antiplasmin activity. Blood Coagul Fibrinolysis $2011 ; 22: 345-8$.

66. Arkebauer MR, Kanaparthy SS, Malayaman SN, Vosseller K, Nielsen VG. Carbon monoxide and nitric oxide modulate alpha-2-antiplasmin and plasmin activity: role of heme. Blood Coagul Fibrinolysis $2011 ; 22: 712-9$.

67. Nielsen VG, Khan ES, Huneke RB. Carbon monoxide releasing molecule-2 enhances coagulation in rat and rabbit plasma. Blood Coagul Fibrinolysis 2010;21:298-9.

68. Nielsen VG, Chawla N, Mangla D, Gomes SB, Arkebauer MR, Wasko KA, Sadacharam K, Vosseller K. Carbon monoxide releasing molecule-2 enhances coagulation in rabbit plasma and decreases bleeding time in clopidogrel/aspirin treated rabbits. Blood Coagul Fibrinolysis 2011;22:756-9.

69. Nielsen VG, Arkebauer MR, Wasko KA, Malayaman SN, Vosseller K. Carbon monoxide releasing molecule-2 decreases fibrinolysis in vitro and in vivo in the rabbit. Blood Coagul Fibrinolysis 2012;23:104-7. 
70. Olver CS, Nielsen VG. Thrombelastographic characterization of coagulation/fibrinolysis in horses: role of carboxyheme and metheme states. Blood Coagul Fibrinolysis 2013;24:273-8.

71. Nielsen VG, Hafner DT, Steinbrenner EB. Tobacco smoke induced hypercoagulation in human plasma: role of carbon monoxide. Blood Coagul Fibrinolysis 2013;24:405-10.

72. Smith MC, Nielsen VG. Detection of carboxyhemefibrinogen and methemefibrinogen in a patient with thrombosis of a Heartmate II ventricular assist device. ASAIO J 2013;59:93-5

73. Nielsen VG, Garol BD, Zelman EA, Guerrero MA. Hemeoxygenase-1 mediated hypercoagulability in a patient with thyroid cancer. Blood Coagul Fibrinolysis 2013;24:663-5.

74. Nielsen VG, Ley MLB, Waer AL, Alger PW, Matika RW, Steinbrenner EB. Plasmatic hypercoagulation in patients with breast cancer: role of hemeoxygenase-1. Blood Coagul Fibrinolysis, in press.

75. Nielsen VG, Lemole Jr. GM, Weinand ME, Baaj AA, Hussaini S, Steinbrenner EB. Brain tumors enhance plasmatic coagulation: role of hemeoxygenase-1. Anesth Analg, in press.

76. Nielsen VG, Gharagozloo F, Matika RW, Kim S, Zelman EA, Steinbrenner EB. Lung tumor effects on plasmatic coagulation: role of hemeoxygenase-1. Lung Cancer, in press.

77. Zhang J, Cao S, Kwansa H, Crafa D, Kibler KK, Koehler RC. Transfusion of hemoglobin-based oxygen carriers in the carboxy state is beneficial during transient focal cerebral ischemia. J Appl Physiol 2012;113:1709-17.

78. Ananthakrishnan R, Li Q, O'Shea KM, Quadri N, Wang L, Abuchowski A, Schmidt AM, Ranasamy R. Carbon monoxide form of PEGylated hemoglobin protects myocardium against ischemia/reperfusion injury in diabetic and normal mice. Artif Cells Nanomed Biotechnol 2013, PMID:23342967

79. Belcher JD, Young M, Chen C, Nguyen J, Burhop K, Tran Phuc, Vercellotti GM. MP4CO, a pegylated hemoglobin saturated with carbon monoxide, is a modulator of $\mathrm{HO}-1$, inflammation, and vasoocclusion in transgenic sickle mice. Blood 2013;122:2757-64.

80. Nielsen VG, Pearson T, Smith MC. Increased carbon monoxide production by hemeoxygenase-1 caused by device-mediated hemolysis: thrombotic phantom menace? Artif Organs 2013;37:1008-14.

81. McColl KEL, Moore MR, Thompson GG, Goldberg A. Treatment with haematin in acute hepatic porphyria. Q J Med 1981;198:161-74. 
82. Simionatto CS, Cabal R, Jones RL, Galbraith RA. Thrombophlebitis and disturbed hemostasis following administration of intravenous hematin in normal volunteers. Am J Med 1988;85:538-40.

83. Barua RS, Sy F, Srikanth S, Huang G, Javed U, Buhari C, Margosan D, Ambrose JA. Effects of cigarette smoke exposure on clot dynamics and fibrin structure: an ex vivo investigation. Arterioscler Thromb Vasc Biol 2010;30:75-9.

84. Pretorius E, Oberholzer HM, van der Spuy WJ, Meiring JH. Smoking and coagulation: the sticky fibrin phenomenon. Ultrastruct Pathol 2010;34:236-9.

85. Pretorius E, Oberholzer HM, van der Spuy WJ, Swanepoel AC, Soma P. Qualitative scanning electron microscopy analysis of fibrin networks and platelet abnormalities in diabetes. Blood Coagul Fibrinolysis 2011;22:463-7.

86. Pretorius E, Oberholzer HM, van der Spuy WJ, Swanepoel AC, Soma P. Scanning electron microscopy of fibrin networks in rheumatoid arthritis: a qualitative analysis. Rheumatol Int 2012;32:16111615.

87. Bao W, Song F, Li X, Rong S, Yang W, Zhang M, Yao P, Hao L, Yand N, Hu FB, Liu L. Plasma heme oxygenase-1 concentration is elevated in individuals with type 2 diabetes mellitus. PLoS ONE 2010;5:e12371.doi:10.1371/journal.pone.0012371.

88. Ebihara S, Kanda A, Maruyama M, Sasaki H, Sasaki T, Yamaya M. Increased arteriovenous carboxyhemoglobin differences in patients with inflammatory pulmonary diseases. Chest 2004;125:1260-8.

89. Takhashi A, Mori M, Naruto T, Nakajima S, Miyamae T, Imagawa T, Yokota S. The role of heme oxygenase-1 in systemic-onset juvenile idiopathic arthritis. Mod Rheumatol 2009;19:302-8.

90. Lipinski B, Pretorius E. Hydroxyl radical-modified fibrinogen as a marker of thrombosis: the role of iron. Hematology 2012;17:241-7.

91. Lipinski B, Pretorius E. Novel pathway of iron-induced blood coagulation: implications for diabetes mellitus and its complications. Pol Arch Med Wewn 2012;122:115-22.

92. Pretorius E, Lipinski B. Differences in morphology of fibrin clots induced with thrombin and ferric ions and its pathophysiological consequences. Heart Lung Circ 2013;22:447-9.

93. Pretorius E, Vermeulen N, Bester J, Lipinski B. Novel use of scanning electron microscopy for detection of iron-induced morphological changes in human blood. Microsc Res Tech 2013;268-71. 
94. Pretorius E, Humphries P, Ekpo OE, Smit E, van der Merwe CF. Comparative ultrastructural analyses of mouse, rabbit, and human platelets and fibrin networks. Microsc Res Tech 2007;70:823-7.

95. Pretorius E, Olivier J, Oberholzer HM, van der Spuy WJ. Scanning electron microscopy investigation of fibrin networks after thermal injury. Onderstepoort J Vet Res 2011;78:e1-4. 